\title{
EXTENSION OF THE SHELF LIFE OF SACHETTED PASTEURIZED MILK
}

By

\section{K.E. Udayathilaka}

B.Sc (specialized in Nutrition and Community resources Management) Rajarata University of Sri Lanka

Thesis Submitted to University of Sri Jayewardenepura for the award of the degree of Master in Food science and Technology on 2003 
The work describe in this thesis was carried out by me under the supervision of Prof. Arthur Bamunuarchci and Mr. R.A.J.N.L. Rupasinghe and a report on this has not been submitted in whole or in part to any university or any other institution for another Degree/Diploma 
I / We certify that the above statement made by the candidate is the true and that this thesis is suitable for submission to the university for the purpose of evaluation

\section{External Supervisor}

Prof. Arthur Bamunuarchci

B. Sc (Cey), M. Sc. Fd. Tech (U.C.D)

Ph.D (N.S.W)

M.I.F.T (U.S.A), A.I.F.S.T. (AUST)

M.A.A.C.C (U.S.A)

M.I CHEM (CEY)

Consultant food scientist \& technologist

Coordinator food science $\&$ technology programmes,

University of Sri Jayawardanapura.

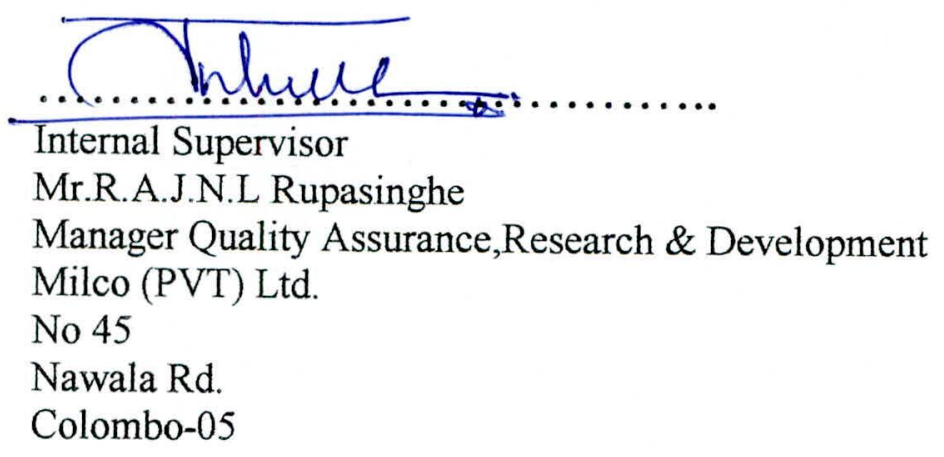




\section{Contents}

Acknowledgements

Abbreviations

List of Tables

List of Figures

Abstract

Contents

\section{CHAPTER 1}

1. Introduction

1.1. Milk 1

1.2. Milk composition 1

1.3. Importance of milk 1

1.4. Scope of the project 2

1.5. Pasteurization 2

1.6. Shelf life improvement 2

1.7. Objectives 3 


\section{CHAPTER 2}

2. Literature review

2.1. Bacteria in raw milk and processed milk 4

2.2. Bacterial of concern in fluid milk 5

2.3. Milk processing techniques 7

2.3.1. Preservation 7

2.4. Pasteurization 8

2.5. Shelf life of fluid milk products 9

2.5.1. Microbial spoilage 9

2.6. Higher pasteurization for increased shelf life? 12

$\begin{array}{ll}\text { 2.7. Post pasteurization contamination } & 13\end{array}$

$\begin{array}{ll}\text { 2.8. The effect of storage temperature on shelf life } & 14\end{array}$

\section{CHAPTER 3}

3. Materials and method 18

3.1. Sampling equipment and containers $\quad 19$

3.2. Sampling technique $\quad 19$

3.3. Numerical selection of samples $\quad 20$

3.4. Storage and transport of samples 20

3.5. Preparation of samples for microbial testing $\quad 21$

3.6. Materials and equipment 22

3.7. Procedures for direct assessment of microbial content of milk 23

3.7.1. Conventional standard plate count method 23

3.7.1.1.Preparation of the growth medium 23

$\begin{array}{ll}\text { 3.7.1.2. Dilution } & 23\end{array}$ 
3.7.2. Coliform colony count method 24

$\begin{array}{ll}\text { 3.7.2.1.Media preparation } & 24\end{array}$

$\begin{array}{ll}\text { 3.7.2.2. Testing procedure } & 25\end{array}$

3.8. Procedures for indirect assessment of microbial content of milk 25

3.8.1. Methylene blue dye reduction test 25

3.8.1.1.Preparation of MBR solution procedure of testing 25

3.8.2. Resazunine test 26

3.9. Other tests 29

3.9.1. Alcohol test 29

3.9.2. Acidity test 29

3.9.3. Phosphatase test 30

3.10. Optimum pasteurization condition 31

3.11. Data recording 31

3.12. Data analysis 31

\section{CHAPTER 4}

4. Results and Discussion

4.1. TCC and CCC variation in different processing points 32

4.2. Influence of pasteurization condition on shelf life 33

4.3. Acidity variation of defferent temp

4.4. Influence of storage temperature on shelf life 36 


\section{CAPTER 5}

5. Conclusion

5.1 Suggestion

References

APPENDIX I ( Row data) 


\section{ACKNOWLEDGEMENTS}

First, I express my deepest gratitude to Prof. (Mr.) A Bamunuarachi, my internal supervisor, for her valuable guidance, excellent advice and wonderful encouragement given throughout this study. I gratefully acknowledge her important and critical comments, which immensely contributed for the success of this study.

I would like to thank my external supervisor Mr. Lakhman Rupasinghe (Quality control manager, MILCO (Pvt) Ltd., Narahenpita) for directing me to initiate the study.

I would like to thank Mrs. Nilani, Mr. Kalpa, Mr. Dissanayaka, and Ms Semini Wijesinha for their help and encouragement during this study. I am thankful for all the workers in MILCO (Pvt) Ltd., Narahenpita who helped me in aware of machinery and in sampling.

Finally, I convey my sincere gratitude to my father, mother, brother who helped and encouraged me in various ways to make this study a success. 


\section{ABBREVIATIONS}

TCC Total Colony Count

CCC Coliform colony count

MBDRT Methylene Blue Dye Reduction Test

MQIP Milk Quality Improvement Program

SPC Standard Plate Count

CFU Colony Forming Units

PPC Post Pasteurization Contamination

LPC Laboratory Pasteurization count 


\section{LIST OF TABLES}

Table 1.1 Quantitative composition of milk

Table 2.1 Heat treatment methods of dairy products

Table 2.2Growth of Non-psychrotrophs and Phychrotrophs

Table 3.1 Materials \& equipment

Table 3.2 Classification of milk quality according to MBR test

Table 3.3 Classification of milk quality according to Resazurin test 


\section{LIST OF FIGURES}

Fig3.1: The flow chart of milk pasteurization process

Fig: 4.1:Bacterial count variation in different processing points

Fig: 4.2: TCC variation in milk packets stored under different temperatures

Fig: 4.3: CCC variation in milk sachets stored under different temperatures

Fig: 4.4: Acidity variation of different storage condition

Fig: 4.5: TCC variation under different pasteurization conditions $\left(<10 \mathrm{C}^{0}\right)$

Fig: 4.6: TCC variation under different pasteurization conditions $\left(10-15 C^{0}\right)$ 


\begin{abstract}
Milk is an excellent source of energy for humans, and yet in a different context. The same nutrients in it provides the most suitable medium for microbial growth and it's metabolism. Hence milk has to be treated with heat to eradicate pathogenic which are associated with milk. The process called pasteurization by which the milk is prepared for human consumption inherits defects due to bad handling by man which demand address. The present day shelf life of pasteurized milk sachets at Milco (Pvt) Ltd., Narahenpita, which is limited to 3 days only. The distribution and marketing of pasteurized milk has become a serious problem.
\end{abstract}

This study is mainly focused to find out the measures, which could be taken within the processing methodology to increase it's shelf life.

The project objectives endeavors to find out the inter relationship between the initial bacterial count and the shelf life of pasteurized milk, the optimum pasteurization conditions, the establishment of post pasteurization contaminations if any and effects of storage temperature on shelf life.

Testing was done on a randomly selected 10 samples, to establish the optimum pasteurization temperature, and time combination in a pilot experiment (maintained temperature at $76^{\circ} \mathrm{C}$ for 40 seconds ) and the results were compared with milk produced with the existing conditions. The evidence of post pasteurization was checked by the detection of Coliform which is an indication of the possibility of post pasteurization contamination. The effect of storage temperature on shelf life was tested, by storing milk sachets at two different temperatures $\left(<10^{\circ} \mathrm{C}\right.$ and $\left.10-15^{\circ} \mathrm{C}\right)$ All these treatment effects were $\mathrm{s}$ analysed through microbiological testings.

In conclusion the present processing conditions proved to be insufficient to hold satisfactory shelf life. It was established that by increasing the time temperature combination of pasteurization to $76^{\circ} \mathrm{C}$ for 40 seconds.

It is not satisfactory with present plant hygienic conditions and chemical sanitization must be applied in addition to thermal sanitization to improve the cleaning programme. Storage temperature after pasteurization is highly effective on the shelf life of pasteurized milk satches and maintain less than $10^{\circ} \mathrm{C}$ is cause for a longer shelf life. 


\section{INTRODUCTION}

\subsection{Milk}

Milk is the fresh lacteal secretion (practically free from colostrums) obtained by the complete milking of one or more healthy cows or buffaloes without the addition of any substances or abstraction of fat or any other constituents. (Specification for row and processed milk, SLS 181:1983.)

\section{Milk composition}

The structures and properties of these components profoundly influence the characteristics of milk and have important consequences for milk processing.

Table 1.1 Quantitative composition of whole milk

\begin{tabular}{|l|l|}
\hline Main constitute & Mean value (\%) \\
\hline Water & 87.5 \\
\hline Total solids & 13.0 \\
\hline Fat & 3.9 \\
\hline Proteins & 3.4 \\
\hline Lactose & 4.8 \\
\hline Minerals & 0.8 \\
\hline
\end{tabular}

\subsection{Importance of milk}

Milk is an excellent source of nutrients for humans, and yet in a different context. These same nutrients for humans provide a most suitable medium for microbial growth and metabolism. Milk, in its natural state, is a highly perishable material, subject to microbial and chemical degradation. 


\subsection{Scope of the project}

MILCO (Pvt) Ltd. is one of the leading dairy processing companies in Sri Lanka. The activities of the company touch on many types of dairy products beginning with yogurt, drinking yoghurt, curd as culture products and ice cream, butter, sterilized milk, pasteurized milk under the brand of "Highland".

This study is mainly focused on shelf life improvement of pasteurized milk sachets. Initially, the existing conditions were analyzed. Based on those conditions, project was focused to find out the measures to improve the shelf life, especially within the processing plant. Samples were taken from different processing points starting from silo to milk packet.

\subsection{Pasteurization}

The public health objective of milk pasteurization is to eliminate all non spore-forming pathogens commonly associated with milk. Pasteurization also effectively destroys a majority of potential spoilage organisms and contributes to product keeping quality under required refrigeration storage.

\subsection{Shelf life improvement}

Food product shelf life is the length of time that a food can be kept under practical storage conditions and still retains acceptable quality characteristics. These characteristics include sensory appeal (odur, flavor, texture, physical appearance) and product safety. 
Low shelf life of pasteurized milk is caused for two main problems.

(1) Distribution of pasteurized milk is limited only for the areas near by the processing plant.

(2) Marketing becomes a problem, as shop owners do not like to buy a product, which is highly perishable.

If we can improve the shelf life of pasteurized milk, it will lead to expand the area of distribution. The processing company can reach the new markets. Marketing will also not a problem as retailers can keep and sell the product for a reasonable time. They do not hesitate to buy the product. Retailers can introduce the product to the new customers, and the demand for product will increase.

The main aim of this project is to evaluate the existing condition in the processing plant and to improve the shelf life of pasteurized milk sachets.

\subsection{Goal and Objectives}

Goal

(1) Shelf life improvement of pasteurized milk sachet

\section{Objectives}

(1) To identify the physical, chemical, microbiological parameters in present milk pasteurization process.

(2) To identify the strength and weakness in the present system

(3) Modify and improve the critical Point and expand the shelf life at least 7days 